\title{
Making Improvements to Product Development within an SME
}

\author{
Harvey L. Kangley, Simon M. Barrans, and Mark A. Newton
}

\begin{abstract}
This paper shares the experiences of a UK based manufacturing small to medium sized enterprise (SME), embedding improvements to a process for new and existing product development (PD). Examples of the improvements include the deployment of advanced tools for capturing the voice of the customer (VOC), creative problem solving and computational design analysis and optimisation.

PD projects and efforts to embed the improvements, within the company, are used as case studies to give examples of the challenges faced, the implications and the corrective action that was taken.

Factors that resulted in waste during development projects usually came from the desire to shortcut the formalised process. Despite the intention of reducing the time spent in development, in the examples given, these actions can result in excess cost and time and in some instances customer dissatisfaction.

SME's have unique challenges in implementing a product development process due to the closeness of senior management to concept generation and prototype production, solutions are suggested.
\end{abstract}

Index Terms-Product development, SME, KTP, engineering processes.

\section{INTRODUCTION}

\section{A. The Company}

A UK based SME, Associated Utility Supplies (AUS) LTD [1], have been successfully developing, manufacturing and supplying bespoke products for the telecommunications, railway and electrical supply industries for 20 years.

Initially, AUS focused on supplying specialist, bought in, products into the industries. Over time, AUS gained the opportunity to become a manufacturer and invested in the machinery and personnel to do so. The capability to create products to a design, paired with the desire to improve existing designs, led to AUS becoming a leading innovator within the industries.

\section{B. The Industry}

The industries AUS supply to are highly regulated, there are significant risks associated with activities carried out in these industries such as working at height, lifting components and working with electricity.

Manuscript received September 25, 2018; revised March 12, 2019. This work was supported by the Technology Strategy Board under Knowledge Transfer Partnership No KTP010705.

H. L. Kangley and S. M. Barrans are with the School of Computing and Engineering, University of Huddersfield, UK. (e-mail: Harvey.Kangley2@hud.ac.uk, s.m.barrans@hud.ac.uk).

M. Newton is with Associated Utility Supplies, Huddersfield, UK (email: mark@aus.co.uk).
If a product is not approved, it will not be purchased by a utility company nor its contractors. The industries have mandatory product approvals processes in place to mitigate these risks and also to ensure lessons are learned from historical incidents. For example, a rail accident led to a train driver receiving a severe electric shock at Sutton Weaver, Cheshire 23 September 2014. The accident report [2] concluded that one underlying factor was that "Network Rail OLE inspections did not include detailed examination of the condition of the auxiliary wire strands within protective sleeves to identify wire strand breakage or fatigue precursor indications possibly present on the wire and/or the sleeve."

The report goes on to make recommendations for improvements to maintenance regimes. It is now required to take these modified maintenance regimes into consideration when designing equipment for these operations.

Utility companies will require evidence of conformance to standards and regulations, be it for a product or a process of design. For example, Design for Reliability is now a mandatory prerequisite for network rail product acceptance. This methodology, as detailed in a Network Rail standard (NR/L2/RSE/100/05) [3] sets out to ensure all new products for the rail industry are designed with reliability in mind. A number of product development tools, many of which are considered best practice, are mandated. Hence, for a company wishing to remain competitive in the rail industry and other regulated industries, it is necessary to become familiar with these best practice tools and to embed them in company systems.

\section{Product Development at AUS LTD}

Over the twenty years that AUS have been developing products, a number of different approaches to product development have been used. Although a high level structured process was never written, a variety of templates exist to guide users through a series of steps in an effort to ensure a level of traceability. This approach has resulted in a range of highly successful bespoke products that have allowed the SME to remain competitive.

More recently, the SME has gone through a period of rapid growth. This growth has, in part, been stimulated by innovation and product development. In light of this, and as customer demand for more regulated and analytical product development became apparent, top management at the SME looked to gain support from local business support advisors who introduced the SME to a local university. The discussions that followed led to the formation of a three year Knowledge Transfer Partnership (KTP) with the following objective [4]: To develop and establish methodologies for innovative product design, analysis and multi-criteria optimisation, in a highly constrained design environment and to apply these to the design of novel products for rail 
electrification.

\section{The KTP Project}

At the time of writing, the project has been running for 15 months and a formalised process for PD has been specified. Steps are now being taken to develop training and guidance documentation. The process has and continues to be embedded and improved as it is used. Regular review meetings act as a forum for discussion and as a means of scrutinizing the process.

This paper will detail and explain the changes that have been made to the product development process at AUS. The challenges that were faced with embedding the changes will be detailed as well as the latest approach to embedding the change.

\section{E. Existing Literature}

Research [5] that looked at data representing 500 manufacturing SME's based in South Yorkshire determined that for an SME to succeed in an intense competitive environment, they "must be proactive toward market opportunities, receptive to innovation and take the lead in new product innovation." The work goes on to highlight weaknesses that may exist within SMEs; specifically poor flexibility and organizational structures that hinder sustained innovation.

The literature concerning PD in SMEs, though limited when compared to that regarding larger enterprises, resulted in the following conclusions:

- Research [6] that debunks common misconceptions and challenges in using Stage-Gate states that the majority of SMEs that are involved in product development do not have a formalised process for product development, and the idea of a formalised process can be daunting.

- - The paper [6] suggests that PD output can be maximized when a level of flexibility lies within the PD process and activities can run simultaneously.

- Research [7] looking specifically at benchmarking best practice approaches to PD in SMEs argues that PD success rates increase when a formalised process is in place.

- An exploration [8] into the problems faced by SMEs trying to implement a process for PD highlighted the following points: "Poor definition of product requirements, technological uncertainty, senior management interference, a lack of resources and poor project management."

- According to [9], research that highlights the barriers between SMEs and successful PD, SMEs may lack the requisite knowledge and often fail to recognize the importance of the product design stage. This is reflected in the lack of use of computational design analysis and optimisation

- PD best practice in industry incorporates tools such as:

Quality Function Deployment (QFD) [10]: transferring the customers' needs into an engineering specification with a focus on quality control.

Stage-gate, as explored in [6]: a process broken into stages with sign-off 'gates' to pass through.

This research was used as the basis for the development of the PD process at AUS.

\section{THE DEVElopment Of THE PROCESS}

\section{A. Initial Findings}

At the start of the KTP project, a review of the existing process and associated documentation was carried out. The existing documentation included:

- Costing log: to record any costs associated with PD

- Design and development form: used for capturing an initial idea or customer enquiry.

- Design and development log: a list of projects and project owners with columns for milestone completion dates.

- Design and development review form: a stage sign off form for reviewing, verifying and validating progress.

- Test reports: although no standardised template.

This documentation acted as a means of ensuring traceability. However, other design and development activities had been carried out by AUS where this documentation had not been used and the process of design and development was determined by the project members involved at the time. Furthermore, development file storage was not standardised - not only in terms of location but also file naming and version control.

When asked to describe the PD process, senior management cited the use of simple sketch drawings followed by the fabrication of an over engineered product that was tested to failure - an iterative process; often involving multiple prototypes and unnecessary costs. This process mirrored the processes described in the literature - a route through PD in SMEs that offers the least resistance [11].

During the process review period it was clear that the existing design and development review form was not embedded nor a value added activity.

\section{B. The Next Steps}

Based on the best practice described in the literature, and KTP team meeting discussions, tools that appeared to fit in with AUS as a business were selected. The tools chosen included 'stage-gate', 'QFD' (initially trialing the House of Quality as a means of transferring the voice of the customer into engineering and design characteristics) and the creative problem solving tool known as TRIZ. Furthermore, computer aided design tools were implemented.

Following the initial review, the file storage system was standardised.

The newly titled 'initial idea/enquiry form' was reworked and designed to become an integral part of QFD at AUS. The form was designed to capture the VOC and ensured deliberate questions were asked, ones often missed historically, that were critical to ensuring customer satisfaction; and that enough information was captured to judge whether a project is worth perusing from a commercial standpoint. For instance: "What is the customer timescale? Please give specific dates.", "Expected sales volume?" and "please describe the business case that justifies the development of the product".

Alongside this, an overall process flow, as outlined in Fig. 1 , was developed in a stage-gate style; end of stage project review meetings were implemented in which resource requirements were weighed up against the potential commercial benefits. Initially, adding mandatory stage gates 
seemed to negate the desire to ensure a flexible process. It soon became apparent, however, that the gated approach resulted in useful discussions - and crucially process users could be flexible within the defined process.

At the end of Stage 1 - in which an initial idea is captured, development projects are reviewed ahead of approval, a design specification created, and concepts created - a concept selection meeting is scheduled to ensure that time is not wasted developing ideas that are not in-keeping with the product's design specification. A description of each end of stage 'gate' can be found in Fig. 1. The process flow, a more detailed counterpart to Fig. 1, which is a controlled document within the AUS quality management system (a system that must reflect actual company process under AUS's ISO 9001:2015 accreditation), reflects the need for flexibility within product development; feedback loops exist to acknowledge the fact that the process is not always sequential; and that some products are not commercially or technically viable to develop.

Also, within the first stage, the process user is given the opportunity to make use of TRIZ - 'the tool for inventive problem solving' - TRIZ was determined to be the best fit for the process but is not mandated; another attempt to ensure flexibility.

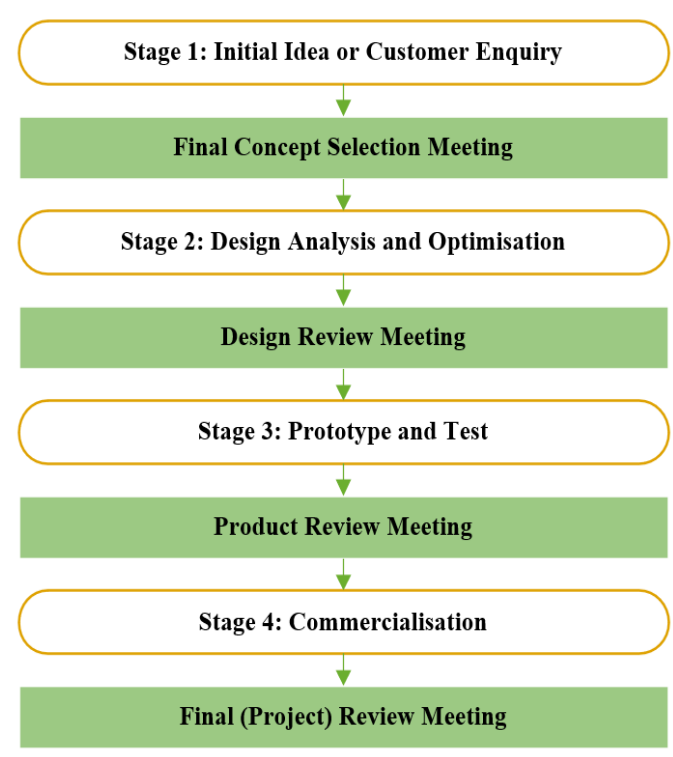

Fig. 1. An outline of the AUS PD process.

Once past Stage 1, when a final concept (or multiple) has been selected, and approved by a company Director, the process ensures attention is paid to design analysis. In line with the objective of the KTP, and to implement the successful use of the tool, a methodology and process for computational design analysis and optimisation is in development to assist this stage. The team must decide, based on costs vs benefits, whether the use of computational design is necessary, or whether a simple hand calculation will suffice. The intention behind this stage is to ensure that the design is right first time and optimized for function. The product's design specification, as agreed upon in the first stage, is used as a reference point in the end of stage meeting to ensure the detailed optimized design is still in line with the original vision.

At Stage 3, a prototype is made according to the detailed design and testing is carried out in accordance with the requirements details in the initial design specification. Another end of review meeting takes placed when tests are successful, and a feedback loop takes the user back to the design analysis stage is the event of failed testing.

Stage 4, the final stage titled 'Commercialisation', emphasizes interaction with the customer during field testing, followed by dialogue with the customer to see how the customer rates the final product. The final stage is closed out with a review of the product development process in an attempt to highlight any kaizen (continuous improvement) opportunities.

\section{DEVELOPMENT PROJECTS: EXAMPLES}

Whilst the process was being developed there were a number of live projects. This proved to be a beneficial approach; process changes could be trialed and a continuous approach to improvement adopted. In some instances, these projects highlighted the dangers of not following the process, in other instances, gaps in the process were highlighted:

\section{A. Project 1}

\section{1) The product (A)}

Industry: Electrical Supply Industry

Application: Electrical protection combined with a mechanical loading requirement: A component of a product for protecting passersby from electrical faults in exposed cables.

\section{2) The risk highlighted}

During the development phase, a number of concepts were selected as being suitable, the decision was made to move to the testing phase. Testing was completed to ensure the component met mechanical loading requirements and the ideal solution was put forward.

Shortly after, an additional customer requirement was highlighted by senior management, the need for additional conformance to separate regulations. This would provide the opportunity to market the final product in other industries. This additional requirement rendered the selected option, and others tested, unsuitable.

Upon review, the issue was that a final design specification had not been agreed upon and an assumption existed that all team members shared the same vision.

\section{3) The effect /impact}

Whilst some value could be taken from the time spent testing, the effect of the change to the initial specification resulted in wasted time, resource and cost. An estimation of the testing costs, as a percentage of the overall project costs, in this case, gives $25 \%-50 \%$. This illustrates the significance of getting the specification right first time.

\section{4) The improvement made}

Based on this project, the PD process includes steps to create, discuss (before a period of concept creation) and regularly refer back to a product design specification assisted by QFD; specifically the HOQ.

\section{B. Project 2}

\section{1) The product (B)}

Industry: Railway

Application: Bespoke, low usage, lifting equipment 


\section{2) The risk highlighted}

Following a request from a highly valued customer, efforts were made by senior management to react quickly to the customer's (seemingly simple) request to slightly modify an existing, rarely used or purchased, bespoke product.

The decision was made, due to the assumed trivial nature of the design change, to go straight to the production of the small batch based on a simple sketch.

Following to the usual procedure, the product was tested to meet the requirements of the safe working load required.

Unfortunately, the test result was a failure and the whole batch became scrap. The cost of the scrapped batch accounted for approximately $80 \%$ of development costs to that point. Due to the commitment made to the customer, development continued.

\section{3) The effect//impact}

Upon closer inspection, it became apparent that the change was not trivial but in fact detrimental to the design of the product; further computational analysis work was required.

Inescapably, the error in project management had a negative financial impact. Despite the efforts made to please the customer, eventually the development costs would exceed the commercial benefit for both AUS and the customer.

\section{4) The Improvement made}

This project was an excellent example of why the process exists, and in fact assisted in embedding a formalised process. All future projects would pass through the process stages as originally intended. This made it clear that too much flexibility in the PD process can in fact have a negative impact on the process. This example allowed the KTP team to find the correct balance in development flexibility for AUS.

\section{Project 3}

\section{1) The product $(C)$}

Industry: Electrical Supply Industry

Application: Bespoke tooling for component installation

\section{2) The risk highlighted}

During the early stages of the KTP, the need for a product improvement was raised. The employee who raised the need for improvement also identified a perceived ideal. The customer was in agreement that this solution would solve the current issue.

The design change was made as proposed and a prototype for trial was produced. During the product trial, another previously unrealized design constraint was highlighted and the 'ideal solution' was now redundant.

During the trial, a deeper understanding of the products application was gained and it was clear that what the customer wanted was not an optimal solution.

\section{3) The effect//impact}

In this instance, waste included design time, production time, material costs and time trialing the initial solution in the field. As a percentage of total project costs at the time the risk was highlighted. The waste accounted for around $60 \%$ of overall project costs

\section{4) The Improvement made}

This project highlighted the need for a robust method for capturing the 'Voice of the Customer', reinforcing the desire to implement quality function deployment at AUS.

\section{Project 4}

\section{1) The product (D)}

Industry: Electrical Supply Industry

Application: Arboriculture

\section{2) The risk highlighted}

At this time, an early version of QFD was in place at AUS and a process for PD had been formalised. An opportunity arose to trial an existing piece of tooling, in conjunction with an AUS tool that promised to meet a customer need; the formalised process seemed to be excessive. This tool is used by arborists for pruning tree branches.

The decision was made to find the easiest method for combining the two tools so a trial could commence. The tool was created and trialed.

In principle, the tool combination was fit for purpose. However, one key requirement, at the time overlooked by the customer, meant that the tool combination could not meet a particular industry regulation and hence the customer's needs.

\section{3) The effect//impact}

As seen in project 1, waste included design time, production time, material costs and further time trialing the initial solution in the field. At the time the issue was realized the waste, in terms of cost, accounted for approximately $25 \%$ of project costs.

\section{4) The Improvement made}

This project reinforced the need for spending time on the early stages of PD and gaining a good understanding of the problem and the needs and wants of the customer - no matter what the size of the project or the perceived level of complexity or novelty.

\section{CONCLUSION}

The main conclusions drawn in the research were reinforced by the examples given in projects one to four in Section III.

The benefits of computational design and analysis are highlighted by Project 1 . Given the simplicity of the design change, a simulation could have determined the effect of the change ahead of production, removing the need to produce any prototypes, with little effect on project duration.

For an SME, the benefits of adding gated stages to the PD process are reinforced by the examples given in III, especially in Project 1.

The examples also reinforce the factors that can hinder PD in an SME, particularly the poor definition of customer requirements.

Whilst the benefits of having a formalised process are not detailed in this paper, clear examples are given of the disadvantages of not following the formalised process. In two of the examples, attempts to shortcut the formalised process resulted in the need to spend additional time developing the product later in the project. The benefits of investing time in the early stages PD are evident in all four of the examples given.

In line with the findings presented in the literature, SME's 
have unique challenges in implementing a product development process due to the closeness of senior management to concept generation and prototype production. One solution to this challenge is a rigorous approach to writing and approving a product design specification, supported by the tools within QFD.

\section{FURTHER WORK}

The Authors are currently looking in more detail at the topic of this paper. Current plans include:

- Interviewing the people responsible for circumventing procedure to determine what their motivation was

- An investigation into whether this motivation can be altered once knowledge of the penalty of not following the PD procedure is more widely known at AUS

- What the cost (time and financial) in circumventing the procedure

- What the cost in following the procedure

- Capturing the use of the tools within the process such as QFD and TRIZ and assessing whether they were beneficial or not.

Another line of thought is that with an improved 'concurrent engineering' approach, improvements would be seen, again, new examples could show this.

Furthermore, more examples could be given to illustrate the current approach to embedding any proposed changes to the AUS PD process. The current approach to implementing change is as follows:

1) Make a proposal to AUS senior management for change to an aspect of the PD process based on research or experiences such as those detailed in Section III.

2) If approved, trial and review - the trial time is dependent on complexity of proposed change. The trial involves the use the new tool or step in a number of development projects ideally by multiple people. The review looks at whether or not the tools or change had a positive effect on the process or not, and if any further changes would be beneficial.

3) Make amendments if required and return to step two, or move to four if approved.

4) Add changes to PD process flow document, - log changes within the AUS quality management system's controlled document log.

\section{REFERENCES}

[1] S. Chen. AUS LTD. (2018). Associated Utility Supplies LTD. [Online]. Available: http://aus.co.uk/acatalog/index.html

[2] Rail Accident Investigation Branch. (September 2014). Train driver receiving a severe electric shock at Sutton Weaver, Cheshire. RAIB.
[Online].

Available: https://assets.publishing.service.gov.uk/media/558803de40f0b615b60 0001a/R072015_150624_Sutton_Weaver.pdf

[3] Network Rail. (2018). Product Acceptance. [Online]. Available: https://www.networkrail.co.uk/industry-commercial-partners/research -development-technology/product-acceptance

[4] Innovate UK. (2017). Partnership details. [Online]. Available: https://info.ktponline.org.uk/action/details/partnership.aspx?id=10705

[5] S. Laforet, "Size, strategic, and market orientation affects on innovation," Journal of Business Research, vol. 61, no. 7, pp. 753-764, 2008.

[6] R. G. Cooper, "Perspective: The Stage-gate ${ }^{\circledR}$ idea-to-launch process-update, what's new, and NexGen systems," Journal of Product Innovation Management, vol. 25, no. 3, pp. 213-232, 2008

[7] N. Leithold, T. Woschke, H. Haase, and J. Kratzer, "Optimising NPD in SMEs: A best practice approach," Benchmarking: An International Journal, vol. 23, no. 1, pp. 262-284, 2016.

[8] J. D. Owens, "Why do some UK SMEs still find the implementation of a new product development process problematical? An exploratory investigation," Management Decision, vol. 45, no. 2, pp. 235-251, 2007.

[9] H. Millward and A. Lewis, "Barriers to successful new product development within small manufacturing companies," Journal of Small Business and Enterprise Development, vol. 12, no. 3, pp. 379-394, 2005.

[10] Y. Akao and G. H. Mazur, "The leading edge in QFD: past, present and future," International Journal of Quality \& Reliability Management, vol. 20, no. 1, pp. 20-35, 2003.

[11] J. McIntyre, Enhancing the SME NPD Process through Customer Focused Design Activities: A New Zealand Case Study, 2009.

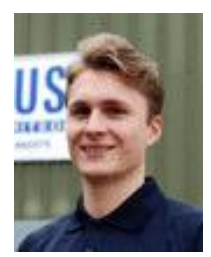

Harvey L. Kangley is the KTP associate of a three year partnership between The University of Huddersfield and AUS Ltd. He obtained his B.Eng. and is currently working toward his M.Sc. at The University of Huddersfield. His research area of interest is product development in SMEs, computational design analysis and multi-criteria optimisation.

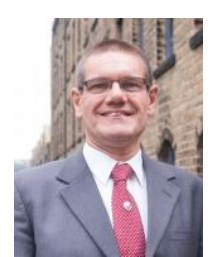

Simon M. Barrans gained a BSc in nuclear engineering from Manchester University in 1987 and a Ph.D in mechanical engineering from Huddersfield University 1996. He is a fellow of the Institution of mechanical engineers and serves on their Academic Standards Panel. $\mathrm{He}$ is also a fellow of the Higher Education Academy. He spent 5 years in the nuclear industry before entering academia. For 8 years he was the leader of the mechanical engineering subject area at the University of Huddersfield. Ove the past 20 years he has supervised a number of $\mathrm{PhD}$ students and has published extensively on topics including air bearings, V-band clamps and multi-criteria optimisation.

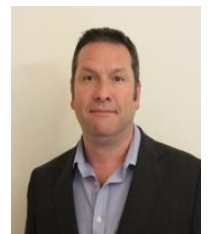

Mark A. Newton gained a BEng in mechanical engineering from the University of Bradford in 1998. He has worked in a number of SME's in several sectors over the past 20 years, but always with an emphasis on manufacturing and planning. Mark is the company supervisor for the KTP between the University of Huddersfield and AUS Ltd. 